\title{
10. From Little Things, Big Things Grow: The rise of Landcare and citizen-orientated land management in Victoria
}

\author{
Jenny Pequignot
}

The singer Paul Kelly's iconic song 'From little things, big things grow' is one of my favourite songs and, I believe, the perfect soundtrack for Landcare - a once little organisation of negligible significance that has grown to be a big one with wide-ranging influence. Landcare, a partnership between government (where I work) and landholders with its origins in Victoria, is the focus of this chapter. The essay is thus about both regional and environmental issues and, in particular, the results of a recent information-gathering exercise.

What is Landcare and how did it come about? Landcare is a collective of community-based and volunteer natural resource management groups, originally comprising a coalition of farmers in north-western Victoria working collectively on land degradation. From these beginnings, Landcare has expanded to become a 'movement', with an estimated 60,000 members in Victoria alone and another 40,000 volunteers in that state. Across Victoria, these individuals have divided themselves into over 1000 Landcare groups, further divided into 62 statewide networks.

Landcare is an example of a grassroots, community-led movement that has replicated itself across Victoria, across Australia and internationally. Moreover, the term Landcare no longer exclusively applies to groups that call themselves Landcare, but various other citizen-led conservation organisations such as 'friends of' groups and Coastcare.

The partnership with government that spawned Landcare was formalised 25 years ago by an exchange of letters between Joan Kirner, the then environment minister in the Victorian Labor government under John Cain, and Heather Mitchell, the then president of the Victorian Farmers Federation (VFF).

A major strength of Landcare is the breadth of local agricultural and environmental knowledge and expertise held by its members. Landcare groups are made up of people that live and work in the same community, and its members are generally involved for significant periods, providing a consistent and stable base with established networks in the community. This attribute is fundamental 
to developing locally relevant solutions to environmental problems, and also arguably makes Landcare a non-threatening way for landholders to get involved in making environmental improvements. After all, in the forum of Landcare, landholders work with peers, who they generally trust, whereas they may not have the same reaction to government involvement in the same issues.

Being an organisation with a local focus, regional differences exist from one Landcare group to another. These regional difference are evidence of the diversity of stakeholders with whom government needs to interact on issues that are relevant to Landcare. In Victoria, for example, Landcare groups in the north-west of the state are typically small-scale and restricted to few networks. In the south of the state, by contrast, Landcare has many networks, and is also a strong lobby group. Networks are important because they reduce the administrative burden on local groups.

\section{The impact of Landcare}

What are the outcomes of this community-led approach to land management? Firstly, Landcare plays a significant role in natural resource management because it mobilises latent local knowledge and capacity to enact both community and landscape scale improvements. Moreover, these environmental improvements are on both public and private land.

Another significant outcome is that social networks that are established through Landcare contribute to the health and wellbeing of communities, so Landcare connects people through a common issue or goal. Landcare groups and networks also work with other local people and organisations to help them with information skills, labour and financial support. Examples include partnerships with schools, community groups, businesses, local government, public land managers and state government agencies. At a private level, Landcare succeeds in addressing long-term land management issues for property holders in Victoria and beyond. Such examples include tackling salinity and fencing off stands of remnant native vegetation.

As far as the current context for Landcare is concerned, there is evidence of an ongoing decline in the state of our environment, which means that the organisation is busier than ever before. There are increasing pressures on the environment through climate change, flood, fire and drought. There are also increasing expectations about productivity and, therefore, more pressure on the capacity of land and increasing demand for clean water. As a consequence, Landcare's local and community volunteer sector is under pressure, with such 
people often filling a gap in small towns where some services, that are usually provided by other actors (such as local authorities, landholders or community bodies), have been lost.

Despite these increasing pressures, Landcare receives limited financial support from government and is also suffering from the consequences of rural migration to cities, which results in a loss of local knowledge and ties to the local community. And, while the so-called 'sea change' or 'tree change' is bringing new people into rural communities, they often have limited local knowledge and skills. We also see absentee landholders, and the consolidation of farm enterprises has sometimes meant that we have land managers, who are less connected with local communities.

\section{Government involvement in Landcare}

The current role of government in the running of Landcare is to essentially invest in the delivery of environmental outcomes for the public's benefit so, although we work with private landholders, what we are most interested in is the public benefit for the environment, which is achieved through the work performed by Landcare groups and networks.

Government also provides annual program funding, particularly for work on the ground, but it also helps Landcare groups and networks provide, capture, promote and share information through a portal, website and quarterly magazine.

In some respects, government is the junior partner in its arrangement with Landcare. Landcare's rationale for existence is not to assume the service delivery responsibilities of government. There are, however, mutual benefits for both parties, with local communities receiving funding and support, and government achieving positive outcomes for the environment and good value for investments - sometimes a fourfold return. Some Landcare groups provide additional support to government through emergency response work in the areas of flood and fire recovery. Moreover, Landcare has been used to liaise between local communities and social networks; for example, on issues such as mental health awareness in drought affected communities.

To achieve optimum outcomes, consultation is conducted between government and Landcare groups, networks and peak bodies to establish the issues to be addressed, and what they desire from government - a process in which I participated earlier this year. The information-gathering exercise involved 10 regional workshops, phone calls and an online survey. 


\section{Findings of the information-gathering exercise}

An interesting aspect of this information-gathering exercise is that it was possible to identify some clear market segments: the peak bodies were interested in a single united voice to government, the networks were more interested in government recognising their capacity and using them to do pilot work, whereas the groups and the volunteers were more interested in receiving more money for on the ground, practical work.

We learned that all tiers of Landcare wanted consistent and longer-term funding for coordinators and facilitators. They wanted support for groups to maintain basic operations, such as insurance cover. Interestingly, they also wanted administrative requirements for project funding to be commensurate with their capacity; in other words that the current reporting requirements are onerous and difficult to comply with. They also wanted recognition that they play an important role in natural resource management and they made it clear to us that they want to be in partnership with government.

Another finding of the information-gathering exercise was a desire to demonstrate the achievements of Landcare among its members. Landcare groups wanted government to help connect groups and networks to share ideas and to learn from each other, and they were keen to strengthen partnerships with other areas of government. They also perceived themselves as providing support and a service not only to the Department of Environment and Primary Industries, but also to health and community services and local government.

An interesting finding from the exercise was that policy directions from government were sometimes seen by Landcare as having a negative impact on the success of its groups and networks. Those consulted were critical of the assets-based approach, according to which it is believed there is not enough money to effectively protect all environmental assets, so the policy involves identifying key environmental assets, then investing in their protection and improvement. From government's perspective this was seen as an improvement on the previous 'Vegemite spread' approach, which neither prevented widescale land degradation nor protected high-value assets. It was apparent from the response of Landcare members, however, that an unintended consequence of the assets-based policy is that Landcare groups working in areas not deemed to have high value assets have missed out on funding to address local priorities.

The findings of the information-gathering exercise highlight the tension between local concerns and state priorities, and more effort should be made by government to better understand what those local priorities are. This does not mean that government should not continue to invest in the key priority assets for the state, but there is an opportunity to work with Landcare groups and 
networks to better communicate why certain areas are key priority assets and how their local work connects to them. In some respects, such tension might be explained by the way a policy has been communicated - it may be a perception rather than a reality.

Landcare was also critical of market-based instruments. These were seen as undermining the fabric of volunteer activity where local landholders were paid to undertake natural resource management activities that formerly would have been carried out by volunteers working together. Consequently, government needs to establish if market-based instruments are building the capacity of local groups or hampering them.

And finally, Landcare stressed a desire to maintain its independence something the membership saw as critically important to allow groups and networks to help themselves.

\section{Issues to address}

So, how might government respond to some of those issues? Firstly, funding for coordinators is an election commitment and is consequently something that will clearly answer a need within the Landcare community. Government will give consideration to the way in which it can meet the need for longer-term funding arrangements, particularly for larger projects. With regard to governance and reporting arrangements, this is an area of design in which capacity constraints must be recognised while, at the same time, retaining accountability. There is clearly, however, a need to reconsider the policy settings to ensure that they are responsive to local needs. Government should be addressing high-value assets and local priorities. The information that is coming through is that there is a real desire to have a partnership approach to regional planning that recognises the impacts of market-based instruments.

As much as Landcare is an example of a successful, citizen-orientated approach to land management, government input is critical to provide groups and networks with technical and scientific information - something they are not always able to develop for themselves. Government is also in a better position to assist with the sharing of information across groups and networks, and it needs to do this by accessing better information from regional communities and responding to it in a way that maintains volunteer capacity. 


\section{Conclusion}

In conclusion, the findings of the Landcare community consultation confirm that, while the public sector has done much right, there is plenty of work to be done to improve the partnership with Landcare. The information-gathering exercise provided us with good information about what we need to do better, namely the need to recognise that groups and networks exist in their own right and have their own local priorities and purposes. Government must understand that there are regional differences between Landcare's volunteer groups, networks and peak bodies, and that each of these have their own, often differing priorities. Better pathways need to established for local information to be shared between regional and state planning networks. And, perhaps most importantly, government needs to recognise local community priorities by adjusting policy settings and streamlining government requirements.

It is important to recognise that the Victorian Department of Sustainability and Environment and Landcare share the common goal of improved land management practices. Working to maximise and nurture the mutual trust and respect that exists between the two organisations should be a priority. From the department's perspective, the community consultation and information-gathering exercise was valuable and insightful and, where Landcare is concerned, it needs to be repeated on a regular basis so as to ensure that policy design and implementation, and the investment of services remains relevant and appropriate. 